\title{
PHYSICAL AND HEALTH EDUCATION FACING THE TECHNOLOGY CHALLENGE
}

\author{
Cristiana Lucretia Pop
}

Physical Education and Sport Department, Bucharest Economic Studies University, Romania

\begin{abstract}
Aim. This essay aims to signal up the detrimental effects of sedentary behaviours determined by extensive use of technology. Material and methods. The paper is a survey of the most relevant data related to physical inactivity consequences with a specific reference to the Eastern Europe countries. Results. There is no doubt that children and young people will prefer the technology and its commodities, but they need to be encouraged to practice exercise, to control their posture and weight. Physical activity favorably influences on mental health and reduces the incidence and severity of diseases and pathological conditions, such as cardiovascular disease, type II diabetes, osteoarthritis, osteoporosis and obesity. Conclusions. Promoting physical activity as a healthy life style component in schools and in universities targets the enhancement of vigour, resilience, employement and social outcomes for graduates and comunities.
\end{abstract}

Key words: Physical inctivity, Globalization, Exergames, Pedagogy, Well-being

\section{Introduction}

The 1990s and 21-st century born generation known as internet, Google or i-Generation; they are digital natives and grow up with internet connection being surrounded with technologies. Television, music, the Internet, smart phones, text messaging, instant messaging, social networks and blogs - all become an integral part of their lives (Rossen, 2010) and all consume more hours a day than in any generation before them.

Internet is already taking a big share of our time, keeping us seated and staring for many hours (days if we are talking about gamers) at a screen. Observing young people I understood what an important change the Internet had made in their communication, learning and behavior patterns. The manner in which i-Gens consume information is vastly different than in previous generations (Schneider, 2015). We are talking already about young generation surfing attitude related to learning and working and also about internet addiction. These constant exposures to the Internet have shaped how they search for and acquire information, how they learn and how they socially interact. In short time they will not need to memorize any more information, because everything will be accessible in one click. At the same time it will be a challenge to act without technological backup. Based on a last decade survey of parents, the researchers estimated that 61 percent of children use screen media (television, videos, DVDs) on a typical day and 43 percent of infants and toddlers watch television every day (Rideout, Hamel, 2006).

Making an imagination exercise we can figure out how the new technology will affect our daily lives. People already work, shop, pay taxes and entertain themselves online, spending less time for transportation and having less interpersonal interactions. For holydays virtual travels in a personal paradise is already a project and feeling the breeze or a friend's handshake without leaving the room is an achievable dream. Domestic robots for housekeeping and easy conversations will be available with Internet (where else?).

Meanwhile, because of Internet addiction, people could suffer a retrogression of imagination, memory and discernment. The sedentary behavior, indoor living in absence of sunlight and fresh air, in addition to unhealthy food will transform most adolescents into flaccid, wick adults with narrow shoulders, underdeveloped lungs, limited physical effort potentials, but really quick in typing. This is not the most optimistic scenario, but in some points is a possible one.

\section{Aim, material and methods.}

This essay aims to signal up the detrimental effects of sedentary behaviours determined by extensive use of technology. The paper is a survey of the most relevant and recent data related with physical inactivity consequences with a specific reference to the Eastern Europe countries.

\section{Results.}

The recent data about youth health, education progress and youth employment rate globaly demande proactive attitude of scholars, politicians and all those involved in education and health system. This paper is a

(C) Cristiana Lucretia Pop, 2016

doi:10.15561/20755279.2016.0207 
pleading for an integrated teaching binomial: health education and physical activity, aiming to develop a resilient workforce and to keep alive the moral values related with constant effort.

Physical inactivity accounts for more than 5 million deaths each year globally (Lee et al, 2012). The estimated proportion of mortality due to physical inactivity ranges from $19 \%$ in Malta to $1 \%$ in Bangladesh. Selfreported physical activity levels vary substantially around the world as well, with 6 countries reporting $90 \%$ or more of the adult population reaching the 150 minutes/week recommended by the World Health Organization and 16 countries reporting $40 \%$ or less of the population meeting physical activity recommendation (Pratt et al, 2015). Romania reported $75 \%$ of adults (age $18+$ years) reaching the recommended physical activity amount with 68 percents for women and 81 percents for men. Also the report estimated that $10.3 \%$ of deaths in Romania are related to physical inactivity, comparing with $9 \%$ worldwide [22]. Ukraine has one of the lowest percentage of mortality associated with physical inactivity (4.9\%) in Europe and the lowest in the Eastern Europe region. $\%$

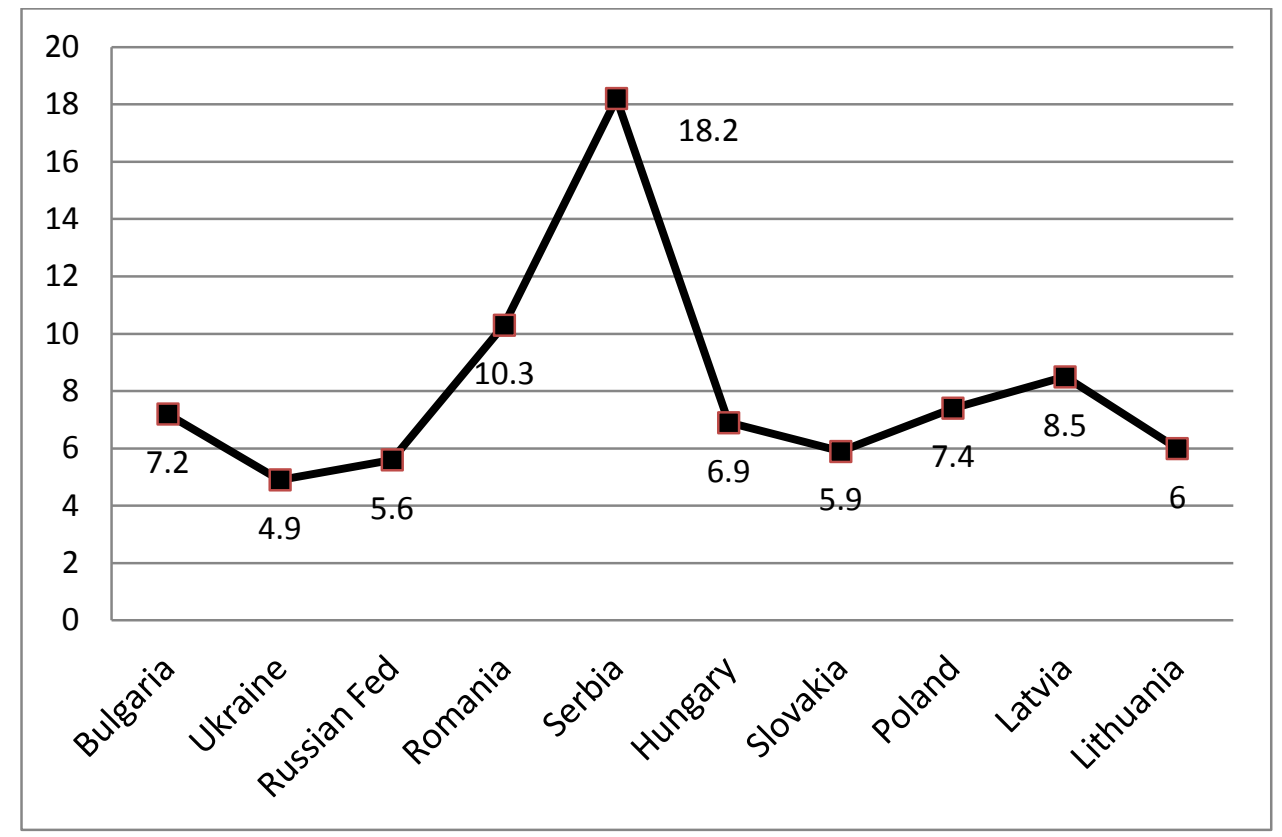

Fig. 1. Mortality associated with physical inactivity (\%)

According to report from the Organization for Economic Cooperation and Development (OECD) entitled „Health at a Glance: Europe 2012“e, obesity in Europe has more than doubled over the past 20 years in most EU countries, for which data are available (OECD, 2010). In addition, the report explains that physical activity among European children tends to drop significantly between the ages of 11 and 15 years. Only $20 \%$ of children practice physical exercises regularly (OECD, 2012). Some researches suggest that children's fitness is in decline because of falling levels of incidental activity, not because of falling levels of participation in sport or other organized activities. Many children practice sports but don't get enough of other forms of activity, things like walking to school or playing in the backyard (Sweet, 2005).

Researchers and physicians, and even non-specialists in physical education and sports domain recommend regular physical exercises for their substantial and sustainable health benefits. Physical activity favorably influences on mental health and reduces the incidence and severity of diseases and pathological conditions, such as cardiovascular disease, type II diabetes, osteoarthritis, osteoporosis and obesity (Ciomag, Dinciu, 2014).

Promoting physical activity as a well-being component in schools and universities targets at enhancement of vigour, resilience, employement and social outcomes for graduates and comunities. Further, health is conditioned by our own habits and behaviour and the accumulation of positive and negative effects in health and well-being is for over the life-course. Therefore cognitive acquisition related to a healthy and active lifestyle would be useful support for physical activity. Improved well-being of youth should contribute to reducing school and 
college/university dropout in the short term, strengthening personal confidence and cognitive function, improving educational efforts and enhancing employability. Integrating physical and health education in preventative strategies would have a real effect on reducing the occurrence of physical and mental disorders and co-morbidities associated with these later, over the life time.

Physical education and sports instructors should have a supporting and encouraging attitude and motivate students for physical effort. The satisfaction gained from exercising can eventually become a motivation in itself, especially when the effort has positive effects on enhancing perceptions of health and overall well-being.

A way to mediate the i-Generation fascination for technology and the beneficial effects of physical activity are the exergames. The energy expenditure from exergaming is similar to skipping, walking or jogging on a treadmill (O'Louglin, 2012) being preferred by children who are already overweight or obese. The main critic against using these means in replacing traditional physical activities is that turns over more energy than sedentary gaming, but not as much as authentic sports, are mainly indoor activities and over time children lose interest in exergaming due to the repetitive nature of some of the games (Bailey, McInnis, 2011).

\section{Discussion.}

Among technology use consequences posterior musculature atrophy could be mentioned, because prolonged sitting position and postural deficiencies associate with "text neck". Bending the head forward and down in a hunched position over a device for typing or gaming causes a higher pressure in the spine. This pressure increases with every degree of head flexing; at 45 degrees, the head exerts $22.5 \mathrm{~kg}$ comparing with $5.5 \mathrm{~kg}$ in normal position (Hansraj, 2014).

Poor posture can have wide-ranging detrimental effects on our body, the most common being: shoulder, neck, and back pain, degenerative disc diseases, kyphosis, tension headache, restricted breathing, depression, increased stress and diminished levels of energy (Peper, Lin, 2012). A hunch posture compresses the internal organs restricting their function and making the body appear heavier.

A bad posture has not only physical consequences, but psychological also: an upright, open, expansive posture is associated with power, self confidence and good mood. When sitting in a collapsed position and looking downward to a smart phone or other screen device, participants in a study found it much easier to recall hopeless, helpless, powerless, and negative memories, than empowering, positive memories (Scutti, 2014).

The contemporary society creates a perfect paradox, promoting, besides this physical effortless life style, idealized bodies, personifying everlasting youth and beauty. The manipulative use of technology in advertising creates unrealistic images of ultra-thin women bodies and muscular, fit males.

Often youth and children are the targets of advertising for high-calorie, high-fat snacks and sugary drinks. The goal of these ads is to sway people to buy these high-calories foods, and often they do. Children are easily tempted by instantaneous pleasures, e.g. sweets, candies or chocolate bars, and they are not necessarily in a position to balance their short-term satisfaction versus their long-term consequences. Companies are exploiting this lack of self control and discernment by the way they provide information to consumers and, for children, it is not easy to understand the permeable boundaries between education, advertising and entertainment (Pop, 2015).

Research shows that exposure to food advertisements produces significant increases in calorie intake in all children and the increase is largest in obese children (Halford, 2007; Montgomery, Chester, 2009). The role of parents is to watch and balance children's diet and therefore their personal example is decisive. A child who has overweight parents, who eat high-calorie foods and are inactive, will likely become overweight too. However, if family adopts healthy food and physical activity habits, the child's chance of being overweight or obese is reduced (Pop, 2013).

\section{Conclusion}

A sedentary life, in conjunction with an increased calories income renders negative influence on new generation's body weight. Overweight and obesity is growing to global proportions, and require urgent and coordinated prevention measures. Education and healthcare systems are attempting a weak counterattack to this aggressive epidemic and to culture of consuming, which pushes rising generation towards greedy lethargy (Pop, 2013). An increased number of adequate physical activities, spending time outdoors, healthy lifestyle programs, or cutting out unhealthy food and beverages in children's meals are a few examples of remedial measures taken in schools and in families. 
The effect of family life style is tracking more then one generation, often overweight and obesity tend to run in families. However, if the family adopts healthy food and physical activity habits, limiting screen activities, the child's chance of getting postural deficiencies or being overweight is reduced.

An obesity prevention program is required in schools, at least at puberty age, when the students are more sensitive to body changes and more self focused. Health and physical education would have made more significant contribution to young people's health and resilience if lessons had been planned and delivered pursuing this specific goal. Also countries like Romania needs a national plan for promoting physical activity in pre-school establishments, schools, universities and among adults through active transportation (walking, cycling), spending leisure time outdoors, or sport competitions in a proper environment.

\section{Conflict of interests}

The author declares that there is no conflict of interests.

\section{References}

1. Bailey BW, McInnis K. Energy cost of exergaming: a comparison of the energy cost of 6 forms of exergaming. Archives of Pediatrics and Adolescent Medicine, 2011;165:120-125.

2. Ciomag V, Dinciu C. The Fitness in physical Education Class - a Determinant Promoter for Student's Health and Body Esthetic. Marathon, 2014;6(2):130-135.

3. Halford JC. Beyond brand effect of television food advertisement on food choice in children: the effects of weight status. Public heath Nutrition, 2007;16:1-8.

4. Hansraj K. Assessment of Stresses in the Cervical Spine Caused by Posture and Position of the Head. Surgical Technology International, 2014;25:277-279.

5. Lee IM, Shiroma EJ, Lobelo F, Puska P, Blair SN, Katzmarzyk PT. Effect of physical inactivity on major non-communicable diseases worldwide: an analysis of burden of disease and life expectancy. Lancet. 2012;219:219-229.

6. Montgomery $\mathrm{KC}$, Chester J. Interactive food and beverage marketing: targeting adolescents in the digital age. J Adolesc Health. 2009;45(3 Suppl):18-29.

7. O’Louglin EK, Dugas EN, Sbiston CM, \& O'Louglin JL. Prevalence and correlates of exergaming in youth. Pediatrics, 2012;130:1-9.

8. Peper E, Lin I-Mei. Increase or decrease depression: How body postures influence your energy level, Biofeedbeack, 2012;40(3);125-130.

9. Pop C. Physical and Health Education for a Resilient Future Workforce. Revista Romaneasca pentru Educatie Multidimensionala, 2015;7(2):133- 140.

10. Pop C. Screen Time Striving with Physical Activities for Next Generation Priorities. Marathon, 2015;7(2):220-224.

11. Pop C. Physical Activities for Overweight and Obese Children - an Inclusive Approach. Procedia - Social and Behavioral Sciences, 2014;163;144-146.

12. Rideout VJ, Hamel E. The Media Family: Electronic Media in the Lives of Infants, Toddlers, Preschoolers, and Their Parents. Menlo Park, Calif.: The Henry J. Kaiser Family Foundation; 2006.

13. Rosen L. Rewired: Understanding the iGeneration and the Way They Learn, St. Martin's Press; 2010.

14. Pratt M, Ramirez A, Martins R, Bauman A, Heath G, Harold Kohl III H, I-Min Lee, Powell K, Hallal P. 127 Steps Toward a More Active World. Journal of Physical Activity and Health, 2015;12:1193 -1194.

15. Scutti S. Change Your Posture To Improve Your Mood, Memory, And 5 Other Aspects Of Your Life. 2014. Available at: http://www.medicaldaily.com/change-your-posture-improve-your-mood-memory-and-5other-aspects-your-life-289724 (accessed 21.11.2015).

16. Schneider J. How to Market to the iGeneration. Harvard Business Review, May 2015. Available at: https://hbr.org/2015/05/how-to-market-to-the-igeneration (accessed 20.02.2016).

17. Sweet M. The big fat conspiracy. Australian Broadcasting Corporation; 2005.

18. Health at a Glance: Europe 2012, OECD Publishing: Paris; 2012;62-65. http://dx.doi.org/10.1787/9789264183896-en

19. OECD/European Union Health at a Glance: Europe 2010. OECD Publishing; 2010:72-73. 
20. World Health Organization. Global status report on noncommunicable diseases 2010. Geneva, Switzerland: WHO Press; 2011.

21. Pedro C Hallal, Rafaela C Martins, Andrea Ramírez. The Lancet Physical Activity Observatory: promoting physical activity worldwide. The Lancet, 2014;384(9942):471-472.

22. Stefan Paul Enescu. Physical Activity Country Card: Romania. Available at: http://www.globalphysicalactivityobservatory.com/card/?country=RO

Information about the author:

Cristiana Lucretia Pop; Professor PhD; http://orcid.org/00000002-6445-8702; crispotir@yahoo.com; Physical Education and Sport Department, Bucharest Economic Studies University; Piata Romana no. 6, sector 1, Bucuresti, 010374, Romania.

Cite this article as: Cristiana Lucretia Pop. Physical and health education facing the technology challenge. Physical education of students, 2016;2:45-49. doi:10.15561/20755279.2016.0207

The electronic version of this article is the complete one and can be found online at: http://www.sportpedu.org.ua/html/arhive-e.html

This is an Open Access article distributed under the terms of the Creative Commons Attribution License, which permits unrestricted use, distribution, and reproduction in any medium, provided the original work is properly cited (http://creativecommons.org/licenses/by/4.0/deed.en).

Received: 04.03.2016

Accepted: 22.03.2016; Published: 25.04.2016 